\title{
Ensino, escola e novas tecnologias: pensamento humano e questões políticas emergentes na era da informática
}

\author{
Francisco José Porfírio Neto*
}

\begin{abstract}
Resumo
Desde o seu nascimento, a humanidade lida com novas descobertas e invenções que, sendo técnicas, tecnológicas e inovadoras, espantam o homem quando são lançadas. Tal espanto não tem, necessariamente, um significado negativo, antes, é o que impulsiona o pensamento filosófico. Uma questão que deve ser considerada diz respeito à maneira pela qual a tecnologia é e pode ser usada, ou seja, diz respeito a sua atualidade e a sua potência. É inegável que as novas tecnologias da informação e comunicação nos trouxeram novas configurações espaço-temporais, novos meios de comunicação, de locomoção e até novas extensões do corpo humano, ampliando a capacidade deste. Ao passo que sua utilização impensada, aliada ao mercado e governos, pode causar efeitos colaterais incidentes nos cidadãos, tais como a vigilância. Tais questões políticas são de extrema importância para se compreender a problemática proposta neste texto, que parte de questões filosóficas, epistemológicas e políticas para chegar ao cenário que abriga a escola e o ensino em meio às novas tecnologias da informação e comunicação e a anunciação de uma crise da modernidade que afeta a educação.

Palavras-chave: novas tecnologias, escola, crise da modernidade.
\end{abstract}

\section{Teaching, school and new technologies: human thinking and emerging political issues in the computer age}

\begin{abstract}
Since its creation, humanity deals with new discoveries and inventions, that been technical, technological and innovative, astonished man when they are released. This amazement has not necessarily a negative meaning, rather, is what drives philosophical thought. One issue that should be considered is the way that technology is used and can be used, in fact, concerns its relevance and its potency. It is undeniable that the new technologies of information and communication have brought new configurations space-time, new media, mobility, until further extensions of the human body, increasing the capacity of this while their thoughtless use, coupled with the market and governments can cause side effects on citizens like surveillance. Those political issues are extremely important for understanding the problem proposed in this text, that start from philosophical, epistemological and political to reach the scene which support the school and the teaching, among the new technologies of information and communication and the annunciation of a crisis on modernity that includes the education.
\end{abstract}

Keywords: new technologies, school, modernity crisis.

\footnotetext{
*Licenciado em Filosofia pela UFG; mestrando em Filosofia pela UFG. E-mail: fjporfirio@gmail.com.
} 


\title{
Introdução
}

\author{
Naqueles tempos, a vida em São Paulo era tranquila. Poderia \\ ser ainda mais, não fosse a invasão cada vez maior dos \\ automóveis importados, circulando pelas ruas da cidade [...] \\ muitas vezes chegando ao abuso de alcançar mais de vinte \\ quilômetros a hora [...]. \\ Zélia Gattai
}

A humanidade, desde seu nascimento, lida com novas descobertas e invenções que, sendo técnicas, tecnológicas e inovadoras, espantam o homem quando são lançadas. Assim aconteceu quando o primeiro ser humano conquistou o domínio do fogo e causou espanto nos demais homens. Sintoma desse espanto foi o surgimento do Mito de Prometeu, semideus que deixou Zeus furioso ao roubar dele o fogo e entregá-lo aos mortais. Igualmente, a escrita causou tamanha reviravolta na história da humanidade que serviu de marco divisório entre a pré-história e a história. A prensa, a locomotiva, o automóvel, o avião, a televisão e os computadores representam apenas alguns exemplos de aparatos tecnológicos que, ao aparecerem no mundo, causaram alvoroço otimista ou espanto, receio, desdém e medo de consequências catastróficas.

Ora, não podemos desconsiderar que muitas das tecnologias descobertas e inventadas pelo homem trouxeram consigo possibilidades tanto positivas quanto negativas. Mas, na maioria dos casos, o impacto resultante da presença dessas tecnologias está condicionado a uma variável essencial: a maneira como utilizamos a tecnologia, ou o aparelho tecnológico, em questão. Para exemplificar, podemos pensar nos aviões que deram ao homem a capacidade de se locomover rapidamente através do voo ao mesmo tempo em que foram utilizados como tecnologia bélica, possibilitando bombardeios e matando inúmeros civis e militares nas guerras travadas nos séculos $\mathrm{XX}$ e XXI.

O fato é que o crescimento vertiginoso da presença da tecnologia na vida da espécie humana nas últimas décadas (sobretudo no domínio da biotecnologia e da informática) atualiza um dos tópicos centrais da reflexão filosófica. Assim, a partir da década de 1930, um dos efeitos mais dramáticos dessa reflexão, podem ser visualizados, por exemplo, nas obras “Admirável mundo novo" de Aldous Huxley e "1984" de George Orwell; distopias que apresentam regimes totalitários utilizando-se da técnica e da razão instrumental para manipular as massas. A manifesta apreensão de setores significativos da intelligentsia ocidental com o descontrolado desenvolvimento da 
tecnologia, por sua vez, impôs-se como um leitmotiv do pensamento europeu desde o entre guerras. A teoria crítica da sociedade produzida pela Escola de Frankfurt à luz da tradição do marxismo ocidental é outro exemplo de pensamento sobre a técnica. Um impulso crítico semelhante pode ser identificado à luz da démarche de Michel Foucault e da acuidade com que este pensador, mais sintonizado com as novas realidades do mundo da tecnologia e suas repercussões no cenário do tempo presente, radicalizou a crítica do capitalismo sob o signo da racionalidade técnico-científica instaurada no alvorecer da modernidade.

A problemática que sustenta a escrita do presente artigo pode ser formulada através das seguintes perguntas: partindo do pressuposto de que as novas tecnologias podem ser aliadas ao ensino, como utilizá-las em sala de aula? Se os nossos alunos deixam, pouco a pouco, de ler e escrever, é possível utilizar as tecnologias a favor da leitura e da escrita? Diante da presença inevitável das novas tecnologias da informação e comunicação (TIC's) no universo escolar e no cotidiano dos alunos, dentro e fora da escola, como as escolas pensam, adotam e convivem com essas ferramentas tecnológicas?

Com base no levantamento de dados bibliográficos expostos neste artigo, podemos adiantar que, de maneira geral, as TIC's têm provocado um incômodo em uma instituição muito cara à nossa sociedade: a escola. Vale lembrar que a palavra incômodo, na pesquisa filosófica, ramo do pensamento do qual partimos neste texto, não tem necessariamente um significado negativo ou pejorativo, pois o mesmo incômodo que nos aflige, pode nos provocar, colocando-nos a pensar, refletir e reagir. Como identificou Paula Sibilia (2012), a escola encontra-se no centro de uma crise, pois fundada na idade moderna sobre o pilar que Pierre Lévy (1997) chamou de tempo da tecnologia escrita, hoje se encontra defasada ao deparar-se com uma nova dimensão, um novo modo de viver e lidar com o mundo, fundados na dinâmica da informação e do conhecimento possibilitada pelas TIC's. A esse novo modo, Lévy (1997) chamou de tempo da tecnologia informática, que através da grande dinâmica proporcionada pelo hipertexto, pela disseminação rápida de conhecimento e, principalmente, pela capacidade de associação simultânea de dados, espalha o conhecimento em uma rede, sendo esta análoga a uma teia. Em outras palavras, essa nova realidade transversaliza o conhecimento, ao passo que a escola tradicional tende a tratá-lo como unilateral, reto, 
estático e cindido, dividido em disciplinas estanques com pouca comunicação entre si e com o mundo exterior. Dado o fato constatado por Sibilia, levamos a cabo neste texto a sua defesa de que em tempos de conexão rápida, em tempos de redes, em tempos de (para utilizar um neologismo cunhado por Pierre Lévy [1999a] cibercultura), urge que a escola se atualize e transponha suas paredes (barreiras) para, então, utilizar as redes de maneira racional, reflexiva, formativa e educativa.

\section{Hipertexto e pensamento}

Vannevar Bush, engenheiro e físico estadunidense, publicou no ano de $1945 \mathrm{seu}$ artigo "As we may think" [Como podemos pensar] no periódico The Atlantic Monthly. Neste texto, o autor apresenta uma intrigante invenção que na época, infelizmente, não saiu da planta. Tratava-se do Memex, abreviação para memory extention [extensão da memória], "projeto visionário de armazenamento e interconexão de todos os documentos produzidos pela humanidade" (POMBO, 2012, p. 255). Sua intenção era criar uma máquina capaz de arquivar e relacionar, de acordo com temas e palavraschave, vários tipos de texto. Para pensar em tal invenção, Bush recorreu às suas observações sobre a mente humana partindo da premissa de que, tal como sua invenção pretendia, a mente humana também funciona por associação de informações. Segundo Bush, o fato de não darmos atenção a essa maneira de nossa mente funcionar dificulta muito nossa vida.

\footnotetext{
Nossa inaptidão para acessar documentos é causada pela artificialidade dos sistemas de indexação. Quando dados de qualquer tipo são armazenados, eles são classificados em ordem alfabética ou numérica, e a informação é encontrada (quando é) traçando um caminho através de classes e subclasses. A informação pode estar apenas em um local, ao menos que se usem cópias dela; existem certas regras para localizá-la, regras estranhamente complicadas. Ao encontrar um item, deve-se sair do sistema e acessá-lo de novo, buscando um novo caminho. A mente humana não funciona desta forma, ela opera por meio de associações. Quando um elemento está ao seu alcance, salta instantaneamente para o seguinte, que é sugerido pela associação de pensamentos segundo uma intricada rede de atalhos contida nas células do cérebro (BUSH, 1945, p. 6) [tradução nossa]
}

Já na década de 1960, Ted Nelson, filósofo e sociólogo estadunidense, utilizou pela primeira vez a palavra hipertexto. O conceito de hipertexto, em linhas gerais, diz de um texto feito para ser lido de maneira não linear devido ao fato de possuir conexões com outras sessões, dentro ou fora do próprio texto, que levam o leitor a rumos 
diferentes (LÉVY, 1999b; LEÃO, 2005; PIMENTEL, 2013). Segundo Pierre Lévy (1999b, p. 41), "hierarquizar e selecionar áreas de sentido, tecer ligações entre essas zonas, conectar o texto a outros documentos, arrimá-lo a toda uma memória que forma como que o fundo sobre o qual ele se destaca e ao qual remete são outras tantas funções do hipertexto informático". Ou seja, "as ideias não precisam ser separadas nunca mais [...] Assim, eu defino o termo hipertexto simplesmente como escritas associadas nãosequenciais, conexões possíveis de se seguir, oportunidades de leitura em diferentes direções" (NELSON apud LEÃO, 2005, p. 21).

O hipertexto, como podemos ver, apresenta uma estreita proximidade com a enciclopédia, pois ambos compartilham da associação de texto como característica própria. O hipertexto, porém, pode ser considerado o limite ideal da enciclopédia (POMBO, 2012). Isso se dá pelo fato de o projeto de conexão entre saberes, possibilitado pela associação de verbetes apresentados na enciclopédia, esbarrar em um problema de ordem prática: a limitação imposta pelo texto impresso. O texto digital, no entanto, oferece suporte para este tipo de associação, tanto é que "os primeiros tipos de texto impresso a serem sistematicamente convertidos em redes computorizadas hipertextuais foram enciclopédias" (POMBO, 2012, p. 252).

Gilles Deleuze e Félix Guattari (1995) identificaram um sintoma recorrente em nossa época que é a compartimentalização dos saberes, fator resultante da divisão do conhecimento em áreas separadas, as disciplinas. Dessa maneira, excluem-se as possibilidades de reconectar as ligações estabelecidas entre as áreas. Ora, esse fato, que hoje se mostra um problema, teve sua origem na modernidade, período em que surge a escola e ganha espaço o espírito científico, sendo delimitados e melhor definidos os campos do saber. Nessa época, o saber e as ciências passam a ser identificados com o paradigma arbóreo, ou seja, os campos do saber são explicados pela imagem da árvore, onde há uma sólida raiz, estabelecida em solo firme, representada pela razão. O tronco principal, por sua vez, representa a filosofia e as demais ramificações representam as tantas ciências existentes. Podemos encontrar um ponto marcante da tese de Bush em Deleuze e Guattari, quando estes afirmam que "o pensamento não é arborescente e o cérebro não é uma matéria enraizada nem ramificada [...]. A árvore ou a raiz inspiram uma triste imagem do pensamento que não para de imitar o múltiplo a partir de uma unidade superior" (1995, p. 25-26). Bush, Deleuze e Guattari defendem que, em se 
tratando de pensamento humano e conhecimento, não existe unidade superior, não existe uno. Esta confusão que há tempos nos engana, bloqueia nossos sentidos para a percepção do múltiplo que a todo tempo nos interpela, nos transpassa.

De 1945, com o já mencionado Memex de Vannevar Bush, até a década de 1960 com o Projeto Xanadu, de Ted Nelson, a ciência se via diante da possibilidade excitante de criar um sistema de indexação no estilo enciclopédico que pudesse reunir, organizar e conectar diferentes textos e conhecimentos. Os esforços rumavam à criação e efetivação do hipertexto, que seria um valioso instrumento ao desenvolvimento científico. Já no ano de 1969, segundo Lucia Leão (2005), as forças armadas estadunidenses desenvolveram a ARPANET, o primeiro modelo do que conhecemos hoje como internet. Esta rede visava, em tempos de Guerra Fria, a possibilidade de uma comunicação segura e eficiente entre os centros de pesquisas dos Estados Unidos. A peculiaridade de tal projeto se manifesta no fato de cada centro interligado pela rede possuir independência da mesma maneira que a rede possui independência de seus pontos de comunicação. Isto possibilita que, caso um ou alguns dos pontos de comunicação deixasse de operar, a rede toda permaneceria ativa. Este modelo de rede de comunicação militar originou a internet tal como a conhecemos hoje.

Em 1991, Tim Burners-Lee, unindo a internet ao já idealizado hipertexto, desenvolveu a World Wide Web (WWW), a plataforma de navegação na internet massivamente difundida nos dias de hoje. A partir desta plataforma simples e interativa e da criação e popularização dos computadores pessoais, chegamos até aqui. Hoje não somente a ciência, mas a educação, as telecomunicações, o entretenimento, as relações pessoais, o comércio, enfim, quase tudo que habita nosso cotidiano está conectado à grande rede. Pessoas de diferentes lugares do globo podem comunicar-se entre si em tempo real. Notícias são rapidamente compartilhadas. O tempo e o espaço foram drasticamente encurtados. Enfim, transpomos, na contemporaneidade, as barreiras geográficas que outrora nos separavam.

\section{Aspectos sociais e políticos das novas tecnologias}

As $\mathrm{TIC}^{\prime}{ }^{1}$ adentraram nosso mundo e a popularização de seu uso, fato que ocorre desde os anos de 1990, tem abarcado uma parcela cada vez maior da população.

\footnotetext{
${ }^{1}$ Sigla para tecnologias da informação e comunicação.
} 
Em contrapartida, infelizmente, grande parte da população ainda encontra-se excluída do meio digital. Enquanto isso, os mercados de bens de consumo e de serviços, aliados às telecomunicações, aprofundam-se cada vez mais nas possibilidades oferecidas por esse novo cenário. Encontra-se um problema: o domínio da rede por grandes conglomerados empresariais, aliados aos governos, é fator desconhecido pela maioria dos internautas e sequer imaginado pelos excluídos digitais ${ }^{2}$.

Recentemente vem crescendo o interesse de certos segmentos da economia, tais como as engenharias (principalmente eletrônica, robótica, genética, agronômica e de alimentos) pela chamada tecnociência. O neologismo tecnociência, criado pelo filósofo belga Gilbert Hottois (1998), surgiu para expressar a ligação entre ciência e tecnologia, descaracterizando, ao mesmo tempo, seus limites individuais sem alterar as características individuais de cada área. Na prática, isto significa que a ciência continua operando a partir do método científico, embasado na busca pela validação de pressupostos, mas ela dá suporte para o surgimento de novas tecnologias. Estas, ao mesmo tempo em que surgem da ciência, passam a dar suporte para que ela siga adiante, formando uma cadeia ininterrupta. $\mathrm{O}$ que vem ocorrendo nesse cenário é uma dominação do mercado sobre a ciência, possibilitada pela tecnociência, pois os recursos financeiros para adesão e criação de tecnologias concentram-se nas mãos dos empresários. Segundo Laymert Garcia dos Santos (2003, s/p),

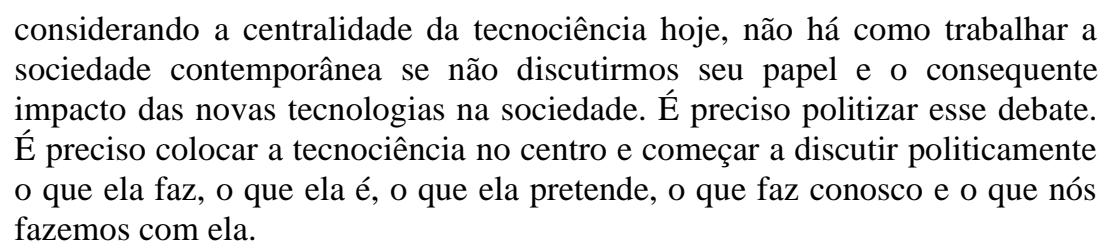

Ou seja, deixar de lado o assunto, enquanto o domínio empresarial se expande sobre as tecnologias, pode acarretar em uma situação de domínio da ciência, por parte da iniciativa privada, onde somente esta teria poder sobre aquela. Isto é nada mais que o ápice da razão instrumental, que agora torna-se domínio do capital.

O domínio empresarial não se interessa somente pela tecnociência, mas também pela informação veiculada através da internet (para fins publicitários), e talvez mais alarmante que isso, os governos se interessam por informações e dados pessoais

\footnotetext{
${ }^{2}$ Conceito utilizado para se referir às pessoas que não possuem acesso às tecnologias digitais.
} 
transmitidos e gravados através da rede. Slavoj Zizek (2011) é radical ao defender que não há democracia no mundo cyberdigital, justamente por conta da dominação dos conglomerados sobre este espaço. Justamente por esse fato surgiram movimentos políticos favoráveis à democracia na internet. Na Europa e nos Estados Unidos, surgiram movimentos como o Partido Pirata, que defende liberdade, democracia e revogação de direitos autorais na rede, o que permitiria livre acesso aos conteúdos de autoria intelectual e artística. Também existem os Cypherpunks, ativistas (hackers) que "defendem a utilização da criptografia e de métodos similares como meio para provocar mudanças sociais e políticas" (ASSANGE et al., 2013, p. 6) na sociedade. Ações como estas se fazem necessárias pelo fato de haver vigilância, de governos e de agências privadas, através da internet. Esta vigilância é facilitada por sites como Google e Face book, pelo fato de armazenarem dados, tais como páginas acessadas, arquivos baixados e conversas pessoais em seus sistemas de arquivamento, denominados nuvens de dados (PARISER, 2012). Julian Assange, homem visado pelo serviço secreto norte americano por ter sido responsável pelo vazamento de dados sigilosos do governo estadunidense quando era editor chefe do site WikiLeaks, chega a prever uma catástrofe caso esse panorama não seja modificado: "se nada for feito, em poucos anos a civilização global se transformará em uma distopia da vigilância pós-moderna, da qual só os mais habilidosos conseguirão escapar. Na verdade, pode ser que isso já esteja acontecendo" (ASSANGE, et al., 2013, p. 21).

A partir da discussão apresentada neste texto, digo que o assunto deva ser tomado, também, pelo seu viés político. As TIC's são ferramentas importantíssimas para a educação, para a ciência e para a economia. Porém, ao não atentarmos para os possíveis efeitos colaterais de seu uso, poderemos cair em uma armadilha fatal. A centralização de um olhar político sobre as TIC's se faz necessária neste momento. Se quisermos uma verdadeira democratização da internet, não basta que as escolas equipem-se com computadores e que a internet chegue a locais isolados. Precisamos levar o debate até a escola para que professores e alunos entendam esse novo cenário e busquem a compreensão não somente técnica das tecnologias, mas também política do problema. 


\section{Como a escola está inserida no debate}

Os jovens de hoje, imersos na rede através das TIC's, deixam, pouco a pouco, de ler e escrever? Os aparelhos tecnológicos são inimigos do professor e da escola? A escola deve resistir à entrada das novas tecnologias em suas dependências? A escola não pode tomar partido das discussões políticas a respeito da internet? Lançamos estas perguntas para que o leitor reflita. Afinal, o que se quer da escola? Qual formação se espera dessa instituição?

\footnotetext{
Muitos professores, educadores e pais se questionam a respeito da juventude que lê e escreve muito pouco, pois "vivem na internet". Observando a internet, percebe-se que é estruturada basicamente com texto escrito. E, quem escreve tantos textos assim? São páginas pessoais, blogs, chats, redes sociais, e-mails, enfim, um apanhado de material escrito produzido por pessoas de todas as idades e, portanto, por jovens também (PIMENTEL, 2013, p. 17).
}

O hipertexto, principal elemento da $W W W$ é composto por escrita, precedida obviamente, pela leitura. Portanto, a acusação de que nossos jovens não leem mais é falsa. A todo tempo, conectados através de seus computadores, smartphones e tablets, nossos alunos estão lendo e escrevendo. O que ocorre é uma vulgarização da utilização destes aparelhos e da internet, que resulta em uma leitura e escrita enfraquecidas (conteúdos pouco relevantes do ponto de vista social, cultural, político e avessa à sintaxe da língua portuguesa devido à sua característica oral e coloquial). Por isso, a defesa que fazemos neste texto insiste que os professores devam adentrar nessa nova realidade juntamente com seus alunos para atuarem como seus guias, evitando que caiam, através desse emaranhado digital, na futilidade, no mau uso das potências.

Paula Sibilia (2012) traça um diagnóstico da situação das escolas nos dias de hoje; estas se encontram em meio a uma crise, pois, fundadas nos pilares científicos da modernidade e emancipatórios do iluminismo, organizadas sob o que Michel Foucault (1999) chamou de poder disciplinar (poder que cria uma estrutura e hierarquia dos corpos com a finalidade de impor-lhes uma disciplinarização, ou seja, de adestrá-los), não encontra mais nos jovens a receptividade exigida. Há uma tendência geral à dispersão. A escola, cercada por paredes, foi transpassada pelas redes e estas são muito mais atrativas, magnetizantes e estão em sintonia com nosso tempo. Bom ou ruim não cabe a nós o julgamento, porém uma problematização pode ser empreendida a fim de deixar claro o complexo cenário sobre o qual dissertamos. Maria Cristina Franco Ferraz 
(2015) recorda passagens de Assim Falou Zaratustra, de Nietzsche, para estabelecer um paralelo com a dispersão da atenção comum no século XXI. Zaratustra, ao sair do isolamento, encontra

\begin{abstract}
uma espécie de 'aleijado invertido' - não alguém que faltasse uma parte [...], mas um ser em que se faltava tudo, menos uma coisa. Zaratustra se depara em seu percurso com uma espécie de imensa orelha ambulante. Olhando melhor, observa que sob essa orelha agitava-se ainda alguma coisa. Descreve, em tom que prefigura Kafka: essa imensa orelha assentava sobre um minúsculo caule, e este caule era um homem. Não um homem qualquer, mas alguém admirado em seu tempo, considerado como um gênio. [...] Esse aleijão, imensa orelha que tudo ouve e absorve sem qualquer filtragem, pode ser lido como um dos efeitos da progressiva exacerbação da cultura da imagem e do espetáculo, que dificulta, senão inviabiliza, o trabalho filtrante e elaborador da consciência (FERRAZ, 2015, p. 15-16).
\end{abstract}

O orelhudo avistado pela personagem de Nietzsche é alguém capaz apenas de absorver informações. Não as filtra, não pensa, apenas absorve e é, com essa atitude, tido como um gênio da época. Ao observamos nosso meio mais de 130 anos após a escrita da referida obra nietzschiana, percebemos como as pessoas têm-se tornado orelhões aleijados. Pequenos gênios transbordam informação que adquirem com admirável fluidez, sem sequer se darem ao trabalho de pensar acerca do produto que recebem. A educação, segundo Sibilia (2012), enfrenta dificuldade ao encontrar tal situação. A transmissão de informação, tão rápida, parece mais eficaz que o saber proporcionado pelo ensino formal. Isso, porém, não significa o fim da escola nem uma corrupção dos jovens pela hiperconexão, mas o sintoma principal para se diagnosticar uma crise institucional que requer uma reavaliação da escola sobre seu papel e seu lugar na sociedade e do professor sobre o seu trabalho. Deixar a crise permanecer é negligenciar uma possível falência da escola em sua função. Urge, neste momento, trazer à tona as potencialidades oferecidas pelas novas tecnologias e procurar a melhor maneira de utilizá-las sem deixar de visar as questões políticas, sociais, culturais e epistemológicas por trás da internet e das TIC's.

Para pensar na educação e no ensino, recorremos à filosofia por enxergar que esta oferece elementos essenciais para se pensar em uma práxis educativa. Podemos pensar, por exemplo, que o trabalho filosófico seja essencialmente constituído pela leitura, pela escrita e pelo pensamento. Partindo do pensamento de filósofos como Deleuze e Guattari, que identificaram um novo paradigma do pensamento e 
reconheceram que a filosofia também se ocupa de questões políticas, é impossível deixar de mencionar o quão frutífero pode ser esta nova configuração social, permeada pelas TIC's, para a filosofia e seu ensino e para a educação e o ensino em geral, que enfrentam uma realidade totalmente diferente da vivida na modernidade: o tempo da dispersão hiperconectada.

Mais que pensar de maneira simplista nas tecnologias como adversárias à educação, é necessário ir ao ponto central: é necessário que a escola, as educadoras e os educadores revejam o seu modo de lidar com a presença da tecnologia na escola, sem pré-julgamentos. Se as tecnologias vão, de fato, favorecer ou desfavorecer o processo de ensino/aprendizagem, ainda há muito o que se discutir, mas essa discussão é urgente. Também não podemos deixar de lado o fato de que, em nosso país, a exclusão digital ainda é gritante, se comparada com países como Uruguai. Desde 2007, o vizinho latino, conforme mostra matéria de Magdalena Martínes, publicada no periódico El País e divulgada em 12 de agosto de 2014, oferece ao ensino público internet banda larga para todas as escolas e um computador portátil para cada estudante. Isso evidencia que, mais que nunca, em tempos de hiperconexão, é necessário também repensar as políticas públicas de educação no Brasil para que o nosso país ofereça os aparatos tecnológicos necessários para se pensar em uma educação pública e de qualidade que possa garantir aos seus estudantes os mesmos recursos tecnológicos que os estudantes das classes média e alta têm em seus cotidianos.

O fato é que há uma crise instaurada em nossos tempos que reflete diretamente na escola. Essa crise pode ser entendida como um descompasso entre o modo de vida das sociedades contemporâneas, hiperconectadas e sem barreiras, e as escolas, ainda muito limitadas pelas barreiras impostas pelo espaço físico. Se a escola está inserida na sociedade, ela não está excluída dessa crise. Pensar em soluções para a superação dessa crise da modernidade é também pesar nas possíveis soluções para a crise do ensino que acomete o nosso país.

\section{Referências}

ASSANGE, J.; et. all. Cypherpunks: liberdade e o futuro da internet. Tradução Cristina Yamagami. São Paulo: Boitempo, 2013. 
BUSH, V. As we may think. In: The Atlantic Monthly, julho de 1945. Disponível em: http://www.theatlantic.com/magazine/archive/1945/07/as-we-may-think/303881 Acesso em 20 jun. 2018.

DELEUZE, G.; GUATTARI, F. Mil platôs- capitalismo e esquizofrenia (vol. 1). Tradução Aurélio Guerra Neto e Celia Pinto Costa. São Paulo: Editora 34, 1995 (Coleção TRANS).

FERRAZ, M. C. F. Ruminações: Cultura letrada e dispersão hiperconectada. Rio de Janeiro: Garamond, 2015.

FOUCAULT, M. Vigiar e punir: Nascimento da Prisão. Trad. Raquel Ramalhete. 23 ed. Petrópolis: Vozes, 1999.

GATTAI, Z. Anarquistas graças a Deus. Rio de Janeiro: Record, 1979.

HOTTOIS, G. Is cloning the absolute evil? In: Human Reproduction Update, v. 4, n. 6 , 787- 790, 1998.

LEÃO, L. O labirinto da hipermídia: arquitetura e navegação no ciberespaço. São Paulo: Iluminuras, 2005.

LÉVY, P. As tecnologias da inteligência: o futuro do pensamento na era da informática. Tradução Carlos Irineu da Costa. São Paulo: Editora 34, 1997 (coleção TRANS).

Cibercultura. Tradução Carlos Irineu da Costa. São Paulo: Editora 34, 1999a (Coleção TRANS).

O que é o virtual? Tradução Paulo Neves. São Paulo: Editora 34, 1999b (Coleção TRANS).

MARTÍNEZ, M. O Uruguai consolida a escola digital. Montevidéu, El País, 12 ago. 2014. Disponível em: https://brasil.elpais.com/brasil/2014/08/11/sociedad/1407771532_215644.html. Acesso em 20 nov. 2018.

PARISER, E. O filtro invisível: o que a internet está escondendo de você. Tradução Diego Alfaro. Rio de Janeiro: Zahar, 2012.

POMBO, O. O círculo dos saberes. Lisboa: CFCUL/Gradiva, 2012.

SANTOS, L. G. A tecnociência no centro da discussão - embora ela não goste. Campinas, Jornal da Unicamp, 8 dez. 2003. Entrevista a Álvaro Kassab. Disponível em: http://www.unicamp.br/unicamp/unicamp_hoje/ju/dezembro2003/ju240pag06.html. Acesso em 27 jun. 2018.

SIBILIA, P. Redes ou paredes: A escola em tempos de dispersão. Tradução Vera Ribeiro. Rio de Janeiro: Contraponto, 2012.

PIMENTEL, C. Blog: da Internet à sala de aula. Curitiba: Appris, 2012. 
170 Polyphonía, v. 30/1, jan./jun. 2019

ZIZEK, S. A liberdade da internet é falsa. Rio de Janeiro, Revista Época, 29 mai. 2011. Entrevista a Nelito Fernandes. Disponível em: http://revistaepoca.globo.com/Revista/Epoca/0,EMI23689415220,00.html Acesso em 27 jun. 2018. 